\title{
Computer-Aided Fit, Tolerances and Limit Gauges Design Using Expert System (EXCAT)
}

\author{
استخدام الحاسب الآلى فى حسابات قيم التجاوزات والإزواجات \\ وتصسيم محددات القياس باستخدام نظم الخبرة
}

\section{By}

\section{I.M. Elewa}

Associate Prof. Dr. of Indust. Prod. Eng. Dept. Faculty Of Eng., Mansoura Unv.

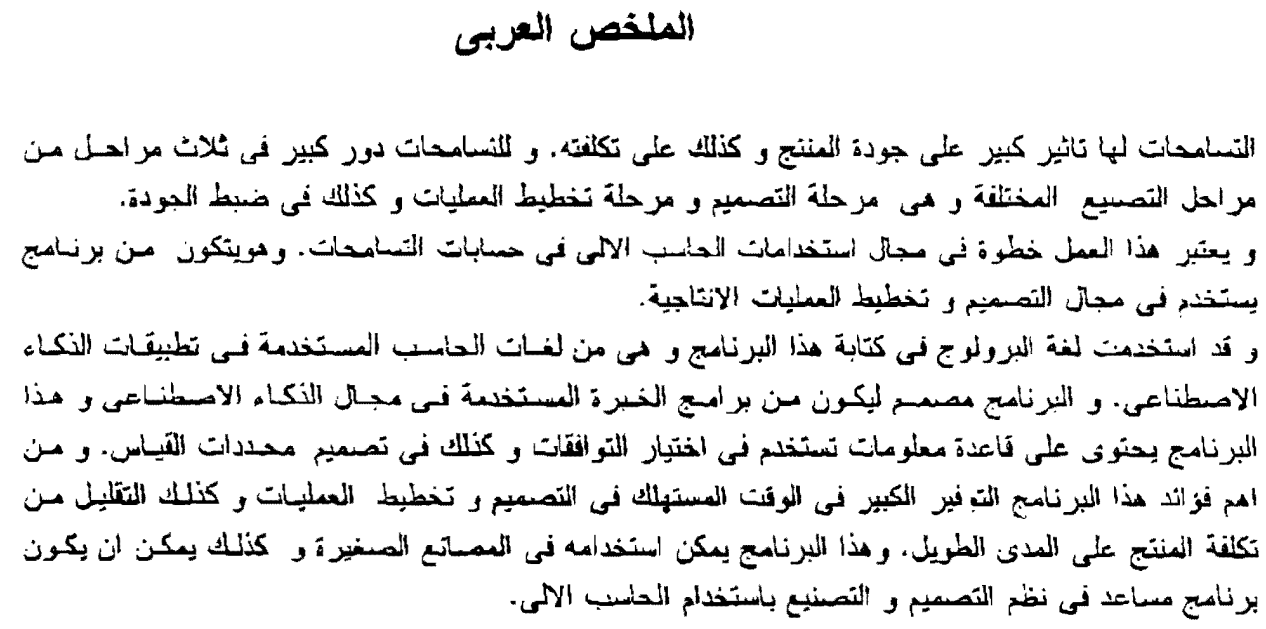

\section{ABSTRACT}

Tolerances and the buildup of tolerances affect the buildability, cost and quality of a product. The effect of the tolerances is so important that there are three major groups in manufacturing organization that are concerned with the tolerances which are design, process engineering and quality control.

This work is a step in the field of computer-aided tolerancing (EXCAT). It consists of a helpful program which has a great important to the production and the design engineers. The program is written with an artificial intelligence programming language which is namely TURBO PROLOG, so the program is structured as mini expert system. For this reason the system contains a knowledge base for fit selections according to the function of the assembly, and limit gauges design. One of the benefits of using of the software is saving in the design and production time and so saving in their costs for the long run. This system is suitable for using in small workshop and also may be linked with CAD/CAM system. 


\section{Kevword}

Tolerancing, Automatic dimensioning, Limit Gauges design, Expert System, Type of Fits.

\section{Introduction.}

An important term linked with mechanical drawing is the tolerance. A close integration of design aspects with manufacture is needed for the success of any product. Tolerancing is one such imponant aspect involving both the designer and the manufacturer [1] Perfect dimensions can not be achieved using presently available processes and machines. Tolerances are hence allocated to the dimension to take care of this limitations. In order to ensure that design requirements are interpreted unambiguasly, industry has developed a methodology for geometric dimensioning and tolerancing [2]. The methodology consists of rules, symbols and their representations. There are many standard available to aid tolerancing. Accordingly several methods are approved by ANSI Y 105, 1973 for expression tolerances in dimensions. One of them is limit dimensioning in which the maximum and minimum limits of size and location are specified. In another method of plus and minus dimensioning, the basic size is followed by a plus and minus expression of tolerancing resulting in either a unilateral or bilateral tolerance.

A comprehensive survey of the basic techniques available for tolerance allocation are presented in [3]. The integration of such techniques with CAD allows for new generation of CADICAM systems. At the present time very little literarure is available showing the implementation of tolerance allocation procedure in CAD systems[4].

Another imporant issue in assembly tolerance allocation involves computer-aided selection of fits. The research in tolerance allocation and selection of fits are closely relared and cannot be separated. Some of researchers describe fully the theory of interference fit and then outline a procedure for computer-aided selection of interference fit using microcomputer $[5,6]$. Knowledge-based system for specification of ISO hits has been described for the manufacture of rotational mating components that cater to interiecence, clearance and transition fits. This rule orient system for compurer-aided tolerancing ROSCA provides the ISO fit that is best suited for the given manufacturing consideration [7, $\left.8^{\circ}\right]$

However as pointed out before, computerized tolerance assignment is no different from the traditional method. In the manual procedure of tolerance attribulion the designer reviews the drawing and sorts out the various features involved in the drawing. Depending on the type of feature, the appropriate tolerance standard is referred. The tolerance is then decided based on the end-use of the feature and its basic dimensions. After this designer incorporates the relevant detail into the drawing. It is felt that this procedure needs to be automated for the factory of the furure. The first and foremost requirements for this is to prepare a computer-aided tolerance (CAT) database of the various tolerance standards. This can be done using any database software. The procedures of reviewing that drawing and inferencing about various features involved in the drawing are not trivial; however, they are rule-oriented or rule based. All the same, this task is extemally important for total automation $\{9,10,11\}$.

The paper identfies a procedure for furure automation the process of tolerance assignment in computer aided drafting as well as the limit gauges design. 


\section{The Model}

The new system consists of a computer program which is considered as a mini expert system. The system has a knowledge base which is used to help the designer to specify the type

of fit and its tolerance limits depending on the function requirements of the fit. This can be done by searching in the knowledge base from top to bottom as shown in figure (1). The system also is capable of performing the limits and fits calculation and producing the tolerance limits. This can be done by searching in the knowledge base from bottom to top as shown in figure (2). The knowledge base contains rules which connect the function requirements and type of fits For example for this rules::

Type of fit ("H8/e8") If it is required Easy nunning fit.

Type of fit ("H7/p6") If it is required Press (Ferrous parts) $5 t$

Type of it ("H8/d9") If it is required Coarse fit

Type of fit ("H8/j7") if it is required Keying fit .

The system can be used to display tolerance zone diagram and the limir gauges (snap and plug) upper and lower limits. It gives also a list of the machines andlor processes that may produce the type of ît in its normal condition. The program is intended to help the designer in the design of the fits and the design of the workshop limit gauges for both hole and shaft It also helps the production engineers in selecting the suitable machines for production of the hole and shaft. The program flow chart is shown in figure ( 3 ).

The calculations which are done by the program are according to ISO standard tables which are namely:

ISO 286-1, 1988 ISO system of limits and fits

Part 1 : Bases of the tolerances, deviation, fits and ISO 286-2 1988, ISO system of limits and fits.

Part 2: Tables of standard tolerance grades and limit deviations for holes and shatts

The calculation for the limit gauges design is based on BS 4500, part 2

\section{Program requirements and lanouage}

\subsection{Program Requirements}

The computer configuration required to run this program are IBM $386 \mathrm{DX} 40$ or its compatible, at least $2 \mathrm{Mb}$ ram, 1.2 Mb disk drive, EGA or VGA card and colour display monitor. The computer additional configuration to run $A C A D$ program are $80 \mathrm{Mb}$ hard disk at least and an input device such as a mouse. The printer which used may be ordinary dot matrix printer with no special requirements.

\subsection{Programming language}

The programming language adopted in this program is Turpo Prolog which is the fifth generation computer language. Prolog is a very powerful tool in programming artificial intelligence applications and in the development of expert system. It is much more powerful and efficient than most other well known programming languages, such as Pascal and Basic. A prolog program gives the computer a description of the problem using a number of facts and rules, and then asks the computer to find all possible solutions 


\subsection{Program description}

The program was designed as a menu driven program tó be flexible and easy to use. It consists of an inference engine with its user interface and provided with a group of knowledge base. The inference engine is the part of the program which performs calculations and control over the knowledge base and the data which imported from the data files. The user interface is the part of the program which generate the user dealt with the screens which display the input

and the output of the program. The data bases which is saved in files in the form of prolog facts are the data needed to run the program.

The program is a stand alone program (executable file) which needs no work through enviroment. The package consists of the following files

\section{EXCAT.EXE The main program \\ HOLE DBA. The file which contains the ISO standard tolerance limits for the hole \\ SHAFT.DBA The file which contains the ISO standard tolerance linvits for the shaft \\ GAUGE.DBA The file which contains BS 4500 for limit gauges design \\ EXCAT.HLP The file which contains the required instruction for help the user to run this program}

\section{How to use the new sustem.}

The program has main menu which appears when the user is starting the EXCAT. The main menu contains several choices which are :

ISO Symbol

Fit Design

Display Tolerance Zone

ACAD Scripi File

Limit Gauge Design

HeIp

Quit

The choice from the menu is done by moving the highlighred bar to the chosen tirle using arrow keys and using Home/End or $\mathrm{PgUp} / \mathrm{PgDn}$ keys for fast jump to the first or the last choices, then Enter key is pressed for selection. You may select the item from the main menu by pressing the first character of the item.

\subsection{Program Facilities}

The new program can perform the following inems.

\section{a. Tolerance limits for Fit or a dimension}

This can be done by selecting the ISO Symbol from the main menu. The user inputs the ISO symbol which represents the fit or the dimension. The program output in this case is

-Type of fit

-The basis system

-The tolerance limits and its fundamental deviations for hole and shaft in case of a fit or for a dimension 


\section{b. Select the proper Type of Fit}

This facility can be obtained by selecting Fit Design from the main menu. For this option the user input the nominal dimension. Then the program will ask the user questions which is answer is (Y/N) to specify the type of fit. That question depends on the function of fit. This options works as mini expert system.

\section{c. Display The Tolerance Zone}

The User can get this option by selecting Display Tolerance Zone. In this option the systern will display the tolerance zone diagram for the last ISO symbol entered or the last fit design. This choice is made to enable the user to see the tolerance zone of the hole and the shaft drawing to realize the clearance or interference between them.

\section{d. Design of Limit Gauges}

This option can be done by selecting Limit Gruge Desiga from the main menu. This choice must be made after calculating the tolerances. It is used to produce the dimension of the limit gauge and it tolerances.

\section{e. Produce ACAD Seript Fije}

The user can get this option by selecting ACAD Script File from the main menu. This opvion is used to produce script file which is used by AutoCad Software to draw the tolerance zone diagram and print it in the paper. This choice adds the facilities of ACAD sofiware to EXCAT

\section{Comparison between the new system and the old system.}

The System is used to help the designer to get the required type of fit depending on the function requirements. It is not required that the designer knows all types of fits but he must know the function of his design. The program, by knowing the function of the fit take the decision and produces the required type of fit.

One of the advantages of the new system presented here is the short time to give the same result compared to the old system. Tthe comparison carried out using theEXCAT to calculate the tolerances for a group of fits and dimensions is shown in the following example.

\subsection{The description of the example}

The example adopted here to evaluate the difference time between the new system and the old system using an assembly which is steam gate vaive as shown in figure (4). in this example the user inputs are the nominal dimension and the iSO symbol for each fit or dimension then the program displays a screen which illustrates the type of fits and the tolerance limits. The results contain the nominal dimension, its tolerance limits, type of fits, tolerance zone diagram, and complete dimension for limit gauges (snap and plug). Some results which obtained from the program are shown in figure (5). Also the calculation of the above example is made using the old model (manual one). The results obtained from both new and manual system are the same but the time which is consumed in calculation and searching in tables is much more. 


\section{Conclusion}

The paper presents an approach for the toleraning of parts and select the proper type of fits incorporating the reasoning employed by the designer and manufacturer. It also gives the user freedom to define tolerance on any feature in the model. Tolerance can be assigned at any time convenient to the user as well as the proper process, machine type and the defauits ase automatically assigned.

As the rule-based system is flexible it can easily be incorporated in an existing manufacturing enviroment.

The old system calculation and searching in tables takes about half an hour. For the completion of calculations and searching in tables for the limit gauges design and drawing. the previous time will be multiplied by 3 . The consumed time for over all calculations will be about one and half hour. When using the new system, it is found that the results are the same while the time consumed by the system to evaluate this caloulation is about is minutes only. The saving time is about $84 \%$ of the time spent in calculations and drawings

Finally, it can be said that the present system (EXCAT) gives a great help to both the design and production engineers. It helps in uninication of their calculations and searching in tables.

\section{References}

1-Etesami, F., 1988, Tolerance verification through manufacturing system, Vol no 3.p223-232.

2.Chase, K.W. and Greenwvop, W H., 1988, Design issues in mechanical tolerance analysis, Manufacturing Revies, Vol. No. 1, p. 50-59.

3-Kaushal P., Shivakumar R. and Simin P., 1992, Computer-aided tolerance assigment procedure (CATAP) for design dimensioning Int. J. Prod, Res . Vol 30 No. 3, P. 500-610

4-Greenwood W.H. and Chase KW., 1987, A new tolerance analysis method for designers and manufacturers, Trans. of ASME, Vol. 109, P. 112-116.

5-Lagodinois A.G. and Scare AJ., 1983, Computer aided selection of interferance fits, Computer in mechanical engineering, Vol. 2, P. 49-55

6-Darwish S., Sallam M. and EL-Taib M., 1992, Computer-aided selection of fit and tolerances, Int. Conf. PEDAC. Alex. Univ, P. 27-29, Dec. Alex. Egypt.

7-Truslove R.C., 1988, The implications of tolerancing for computer-aided mechanical design. Compurer aided engineering joumal, Vol. $S$ No. 2, P. 79.85.

8-Manivannan S., Lehtihet A." and Egbelu P., 1989, A knowledge based system for the specification of manufacturing tolerances, J. of Manuf, Systęm, Yo: 8 No: 2.P: $1.53-160$

9.Wange H. and Wysk R, 1988, A knowledge-based approact for automared process planning. Int J. of Prod. Res., Vol. 26 No. 6, P. 999-1014.

10-Janakiram D. Prasad L. and Rao U., 1989. Tolerancing of parts using an.expert system. Int. J. Adv. Tech., Vol. 4, P. 157-167.

11-Parkinson D. 1986, Tolerancing of parts in CAD, CAD Journal, Vọl 16 No. 1,23-32. 
Mansoura Engineering Jounal (M.E.J.) Vol. 20, No. 1, March 1995, M.109

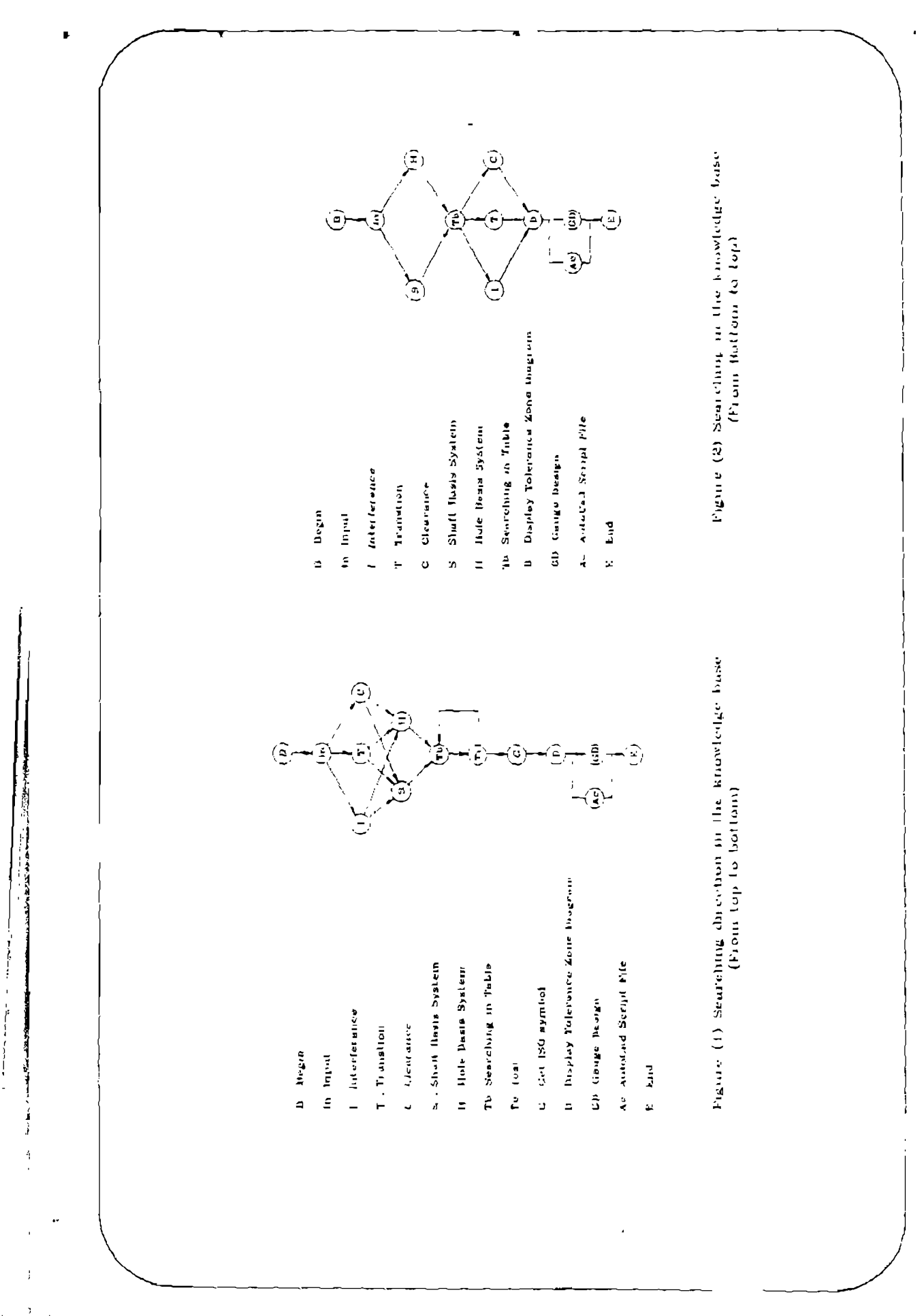




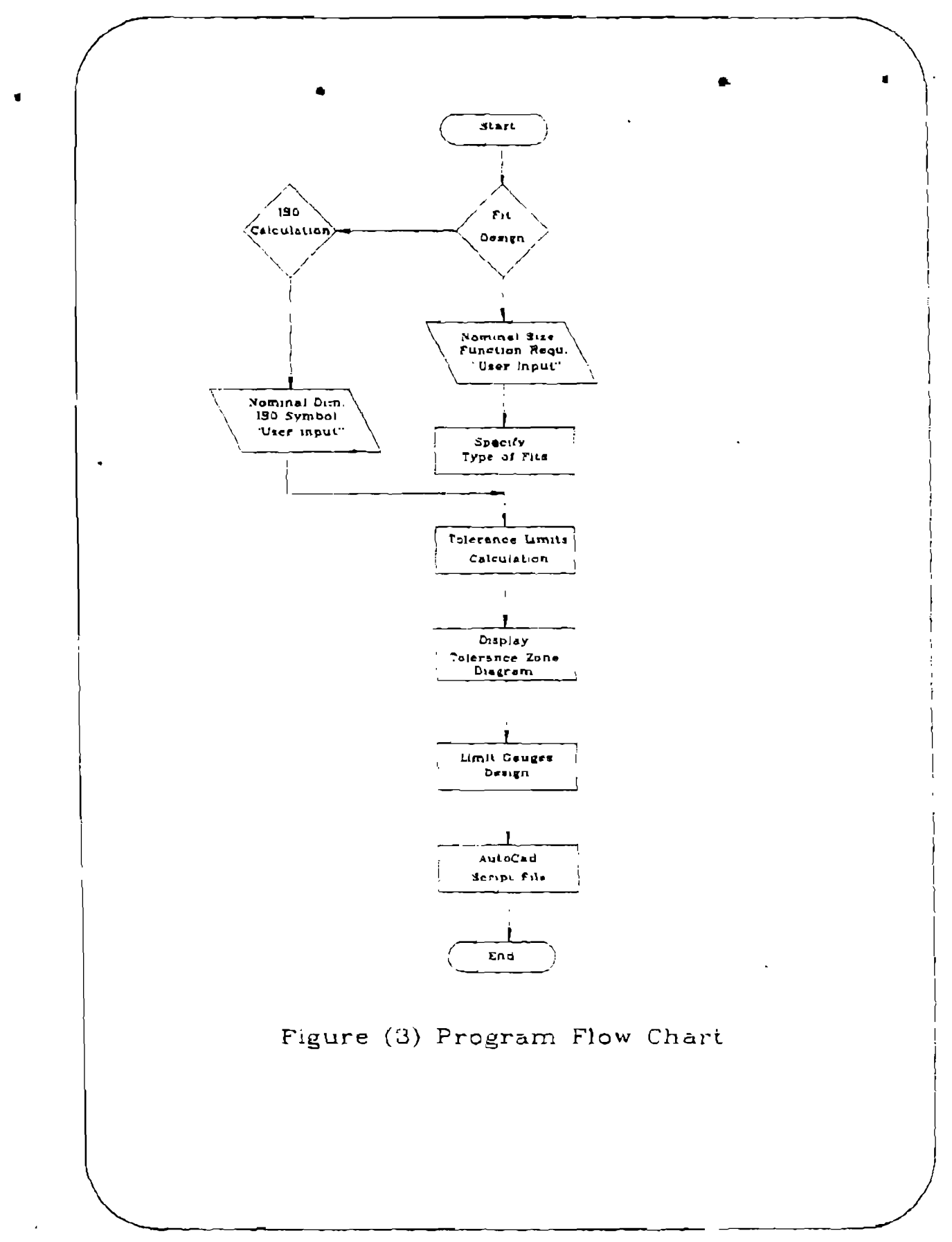


Mansoura Engineering Joumul (M.E.J.) Vol. 20, No. I, Murch. 1995, M.111

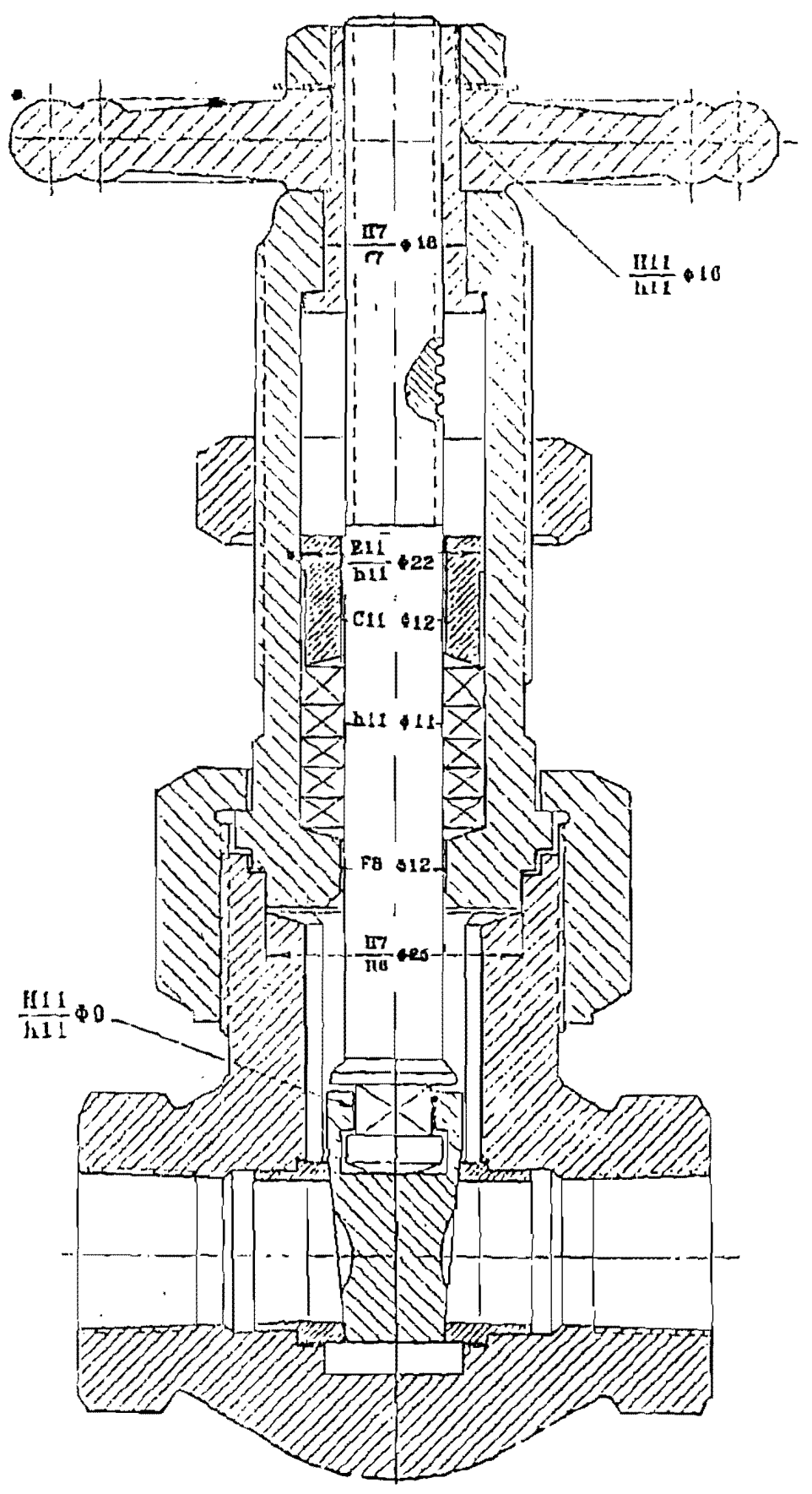

Figure (4) Steam gate valve 

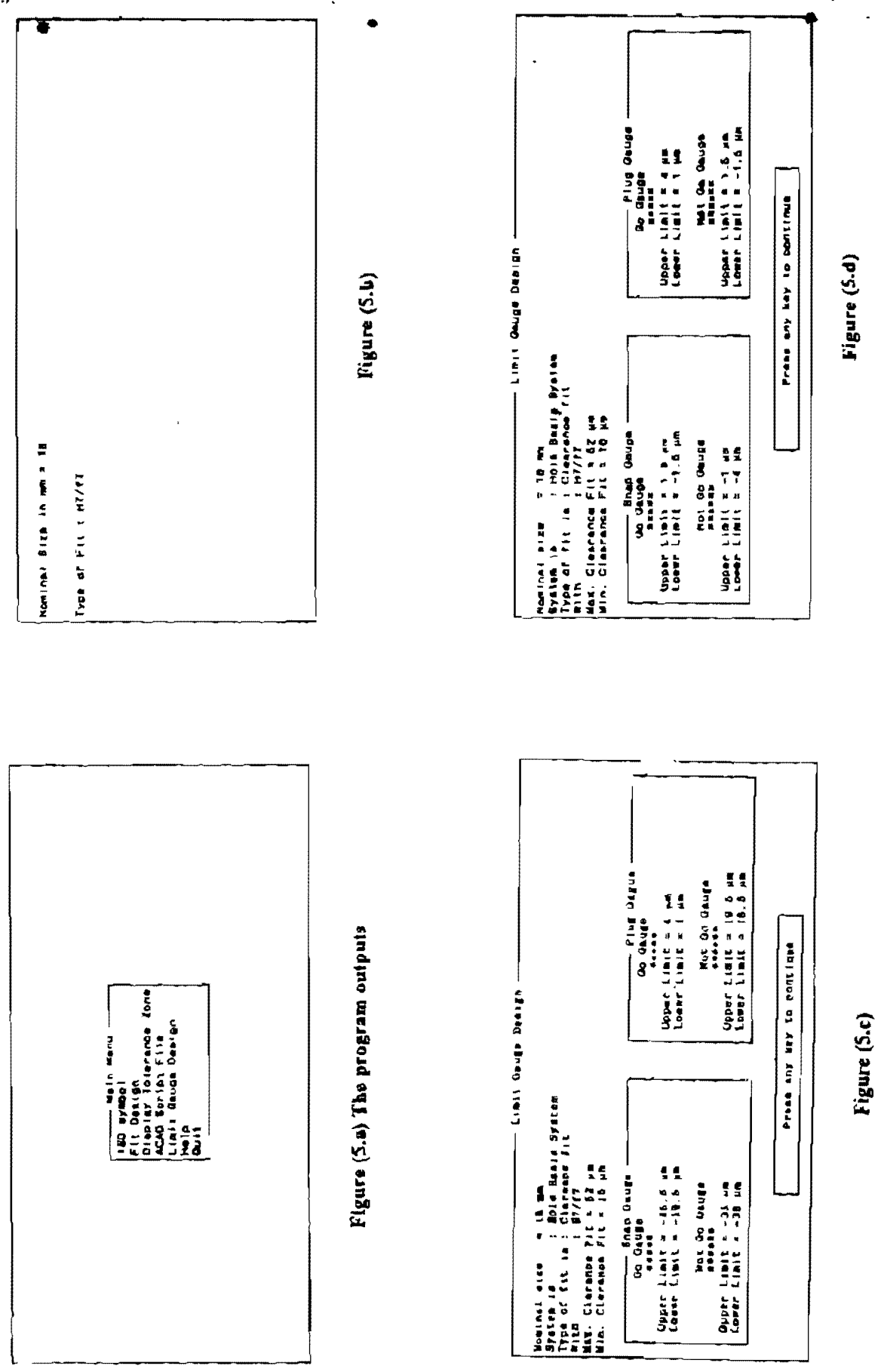


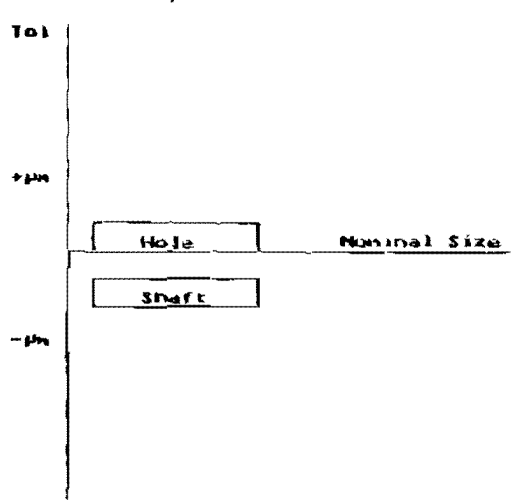

Tolerance Zone Daigram

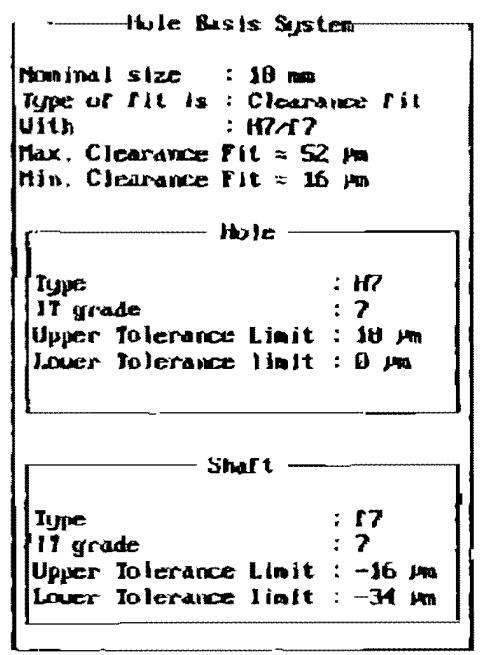

Figure (5.e)

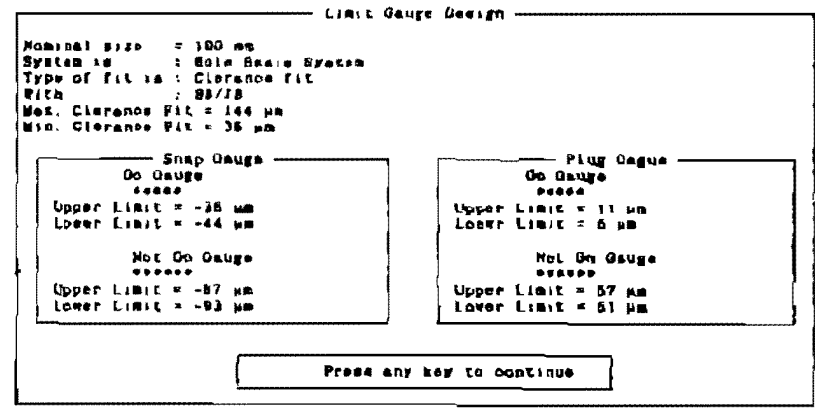

Figure (5.g)

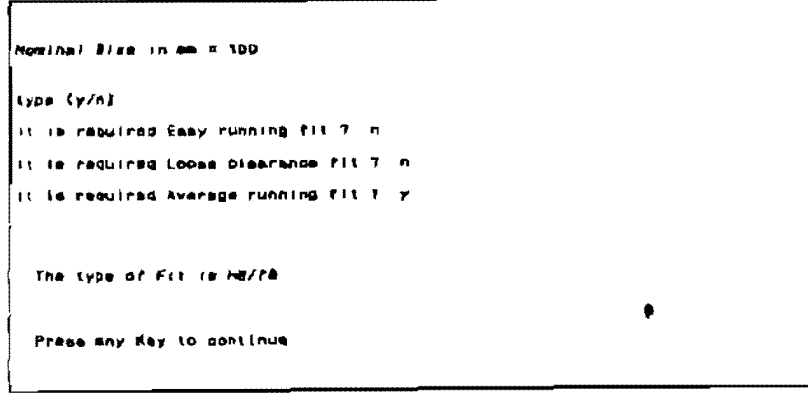

Figure (5.)

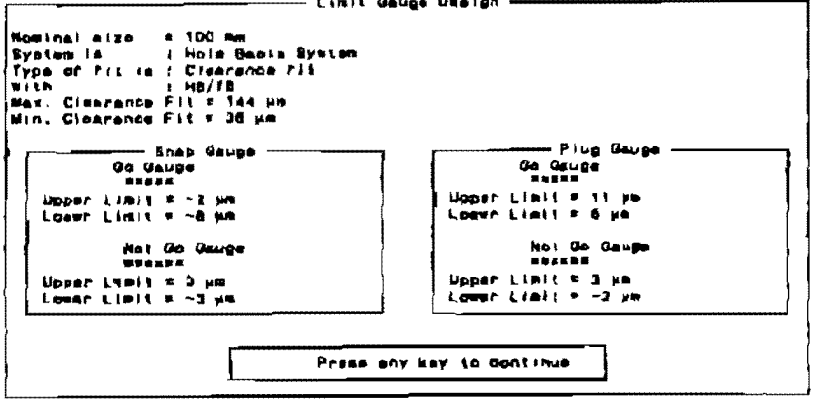

Figure (5.h) 

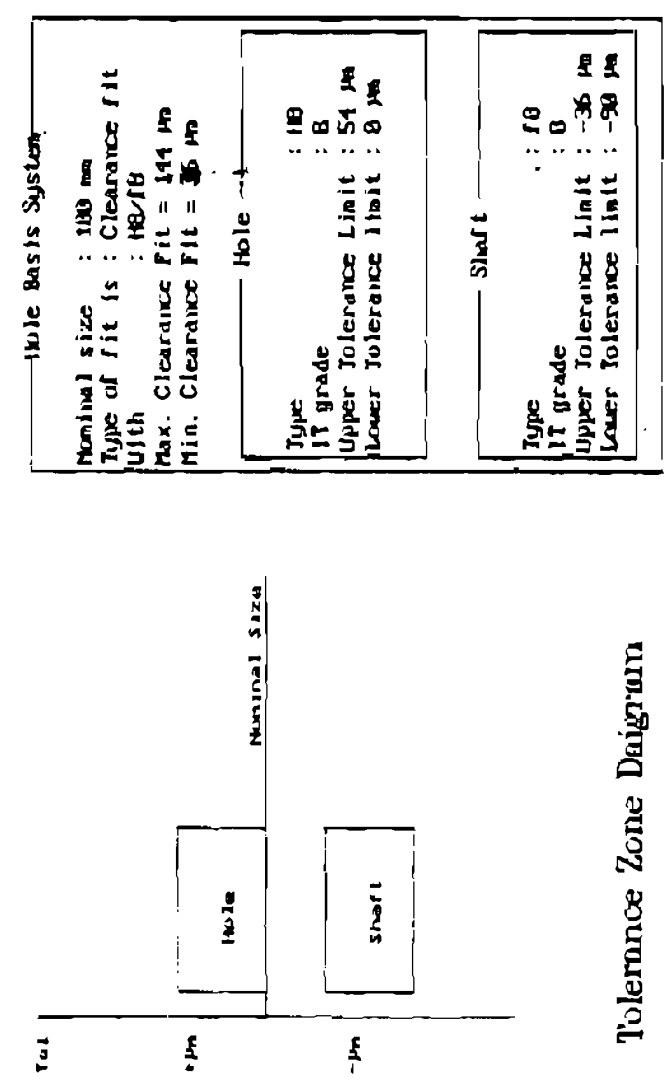

3
0
0
0
0
0
0

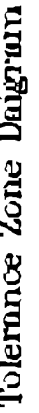

